\title{
VIRTUAL RECONSTRUCTION OF THE ALMAQAH TEMPLE OF YEHA IN ETHIOPIA BY TERRESTRIAL LASER SCANNING
}

\author{
M. LINDSTAEDT ${ }^{1}$, K. MECHELKE ${ }^{2}$, M. SCHNELLE ${ }^{3}$ and Th. KERSTEN ${ }^{1}$ \\ ${ }^{1}$ HafenCity University Hamburg, Photogrammetry \& Laserscanning Lab, Hebebrandstraße 1, 22297 Hamburg \\ (maren.lindstaedt, klaus.mechelke, thomas.kersten)@ @cu-hamburg.de \\ ${ }^{2}$ HafenCity University Hamburg, Geodetic Lab, Hebebrandstraße 1, 22297 Hamburg \\ ${ }^{3}$ Sana'a Branch of the Orient Department, German Archaeological Institute, Berlin, Germany, ms@orient.dainst.de
}

KEY WORDS: archaeology, cultural heritage, terrestrial laser scanning, virtual, reconstruction, 3D, meshing

\begin{abstract}
:
In autumn 2009 the Almaqah Temple of Yeha in Ethiopia has been recorded by terrestrial laser scanning and digital photogrammetry in cooperation between the Sana'a Branch of the Orient Department of the German Archaeological Institute and the HafenCity University Hamburg. The temple dates from the 7th Century BC and is one of the best preserved buildings of Sabaean architecture in Africa. As a basis for all future project works a geodetic network was established in UTM-coordinates by GPS measurements. The geodata collected will form the basis for all future work on the temple. The deformations of the facades were determined for restoration issues and the existing parts of the temple were modelled by meshing (3D triangulation). Using the scanned point cloud and a technical analysis of the building the Propylon, which is no longer existent today, was virtually reconstructed. In future, the data will also be included in the master plan for touristic development of the region of Axum and Yeha in northern Ethiopia.
\end{abstract}

\section{INTRODUCTION}

Terrestrial laser scanning has been established as an efficient technique for the documentation of archaeological sites and research objects as well as for excavation sites. Due to the feature of scanning the object with a very dense number of points, nowadays laser scanners are often preferred to a total station. The excavation work has not to be interrupted for long time if a laser scanner is used. The conditions of a certain excavation status can be presented in a very detailed map on the computer screen and can be analysed later in a later stage, even if the excavation is already continued or finished. According to the demands of the archaeologists, the simple point cloud or a 3D model of the object can be used for analysis. Even if no excavation work is carried out, the use of multiple sensors for the documentation of historical sites and cultural monuments is increasing. Remondino et al. (2009) used not only a laser scanner, but also aerial images taken from an UAV for the modelling of the former Maya city of Copán. For the documentation of the Erechtheion in Athens El-Hakim et al. (2008) have used laser scanners of different ranges with different accuracies together and combined the data with digital images.

The presented project is a cooperation of the HafenCity University Hamburg and the Sana'a Branch of the Orient Department of the German Archaeological Institute. It was established several years ago and so far some objects in Yemen have been already recorded and modelled, such as the Almaqah Temple in Sirwah (Lindstaedt et al., 2008) or the great dam in Marib (Kersten, 2007). The acquisition of the Almaqah Temple of Yeha was carried out by terrestrial laser scanning and digital photogrammetry in this campaign, although the later use of photogrammetric data processing (for modelling or texture mapping only) was not finally defined. In addition to the documentation of the current status of the 2700 years old temple for necessary restoration work, a model of the original temple condition should be generated. Therefore the point cloud was used as a basis for the reconstruction regarding technical building research aspects. The result is not only useable for further archaeological investigations, but can be also integrated into the master plan for the touristic development of the regions of Axum and Yeha in northern Ethiopia.

\section{THE ALMAQAH TEMPLE OF YEHA, ETHIOPIA}

The Almaqah Temple of Yeha is located in northern Ethiopia, about $30 \mathrm{~km}$ northeast of the city of Adwa. The Sabaean temple construction is dated to about $700 \mathrm{BC}$. The dimensions are about $18 \mathrm{~m} \times 15 \mathrm{~m}$, the original height was more than 14 meters. The walls are built of up to 3 meters long stones without any use of mortar. They are very flat and the stones are manufactured with great precision, so that joints between them are hardly developed. In general, the walls are very well preserved, at one part of the facade even the original final stone still remains on the top. Above the entrance on the western façade a U-shaped outbreak of the masonry is visible (see Figure 1).

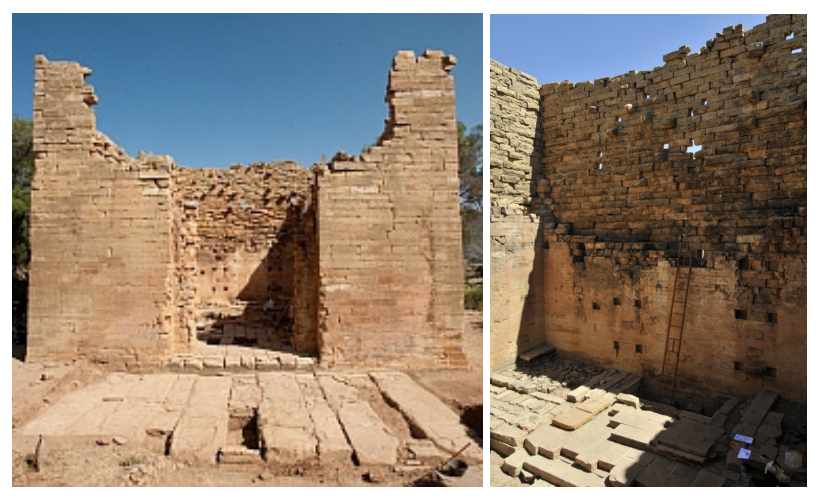

Figure 1: The Almaqah Temple of Yeha, Ethiopia, view from west (left), eastern façade inside the Temple (right) 
Inside the temple with the height of about 6 meters a second wall connects to the outside wall, which still has its original height at several places. In the entrance area a foundation is located, from which the existence of a former propylon can be derived, which is totally destroyed today.

\section{DATA ACQUISITION}

The object recording of the temple was carried out using the terrestrial laser scanner IMAGER 5006 from Zoller + Fröhlich $\mathrm{GmbH}$ (see Fig. 3 left). The scanner works with the phase difference method in an unambiguous range up to $79 \mathrm{~m}$. Technical specifications of the IMAGER 5006 can be found in Table 1, investigations into the behaviour and accuracy of the scanner are published in Kersten et al. (2009).

\begin{tabular}{|c|c|c|}
\hline \multicolumn{2}{|c|}{ Scanner/Criterion } & $\begin{array}{c}\text { Z+F } \\
\text { IMAGER 5006 }\end{array}$ \\
\hline \multicolumn{2}{|l|}{ Scan method } & Phase difference \\
\hline \multicolumn{2}{|l|}{ Field of view } & $360^{\circ} \times 310^{\circ}$ \\
\hline \multicolumn{2}{|l|}{ Scan distance } & $<79 \mathrm{~m}$ \\
\hline \multicolumn{2}{|l|}{ Scanning speed } & $\leq 500000 \mathrm{pts} / \mathrm{s}$ \\
\hline \multirow[t]{2}{*}{ Angular resolution } & Vertical & $0.0018^{\circ}$ \\
\hline & Horizontal & $0.0018^{\circ}$ \\
\hline \multicolumn{2}{|l|}{ 3D scan precision } & $10 \mathrm{~mm} / 50 \mathrm{~m}$ \\
\hline \multicolumn{2}{|l|}{ Camera } & add-on option \\
\hline \multicolumn{2}{|l|}{ Inclination sensor } & yes \\
\hline
\end{tabular}

Table 1: Technical specifications of the IMAGER 5006

The data acquisition was part of the autumn campaign in October and November 2009. In total six days of work for 58 scan positions were used, where the pure scanning time was about twelve hours. To cover the object totally, scanning was performed from the ground and also from elevated positions (Fig. 2). Wooden scaffolding with a height of twelve meters was erected to scan even the top of the building.
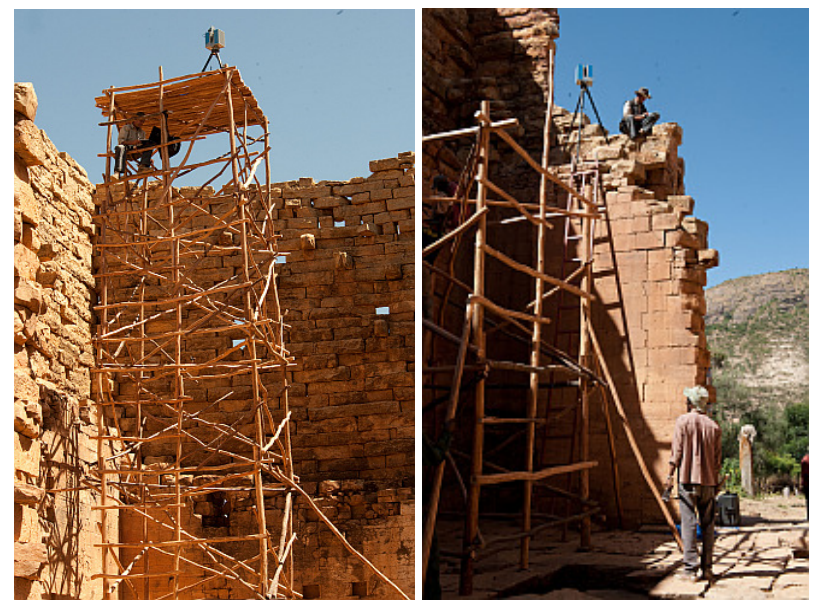

Figure 2: Scanning on scaffolding (left) and on top of the wall (right) using the IMAGER 5006 from Zoller + Fröhlich

The scanning resolution was set to "high"(6.3mm@10m), which amounts to $25 \mathrm{~GB}$ of data per scan. For the colouring of the point clouds a Nikon D40 (with $18 \mathrm{~mm}$ lens) was mounted on top of the scanner or a nodal point adapter with a Nikon D200 (with 14mm lens) was used as illustrated in Fig. 3 (right). The colouring of the scans was performed in an automated process using the software Z+F LaserControl (Fig. 4).
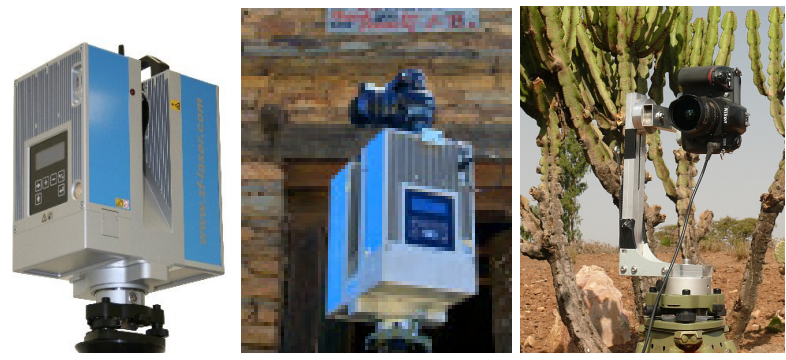

Figure 3: Laser scanner IMAGER 5006 (left), with mounted Nikon D40 camera (centre) and Nikon D200 camera on nodal point adapter

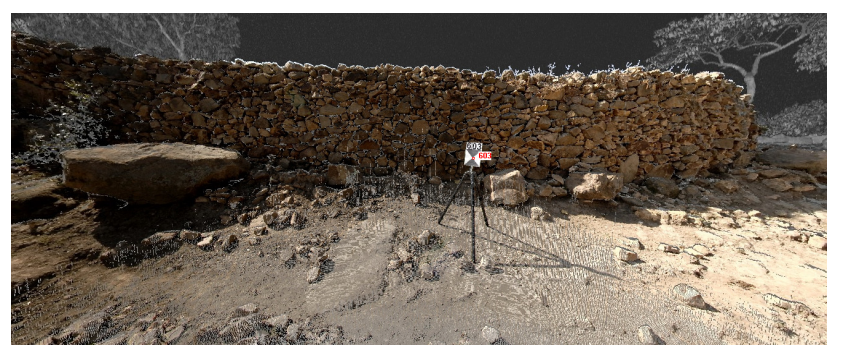

Figure 4: Coloured point cloud of the IMAGER 5006 using the images of the Nikon D200, which was mounted on the nodal point adapter, in LaserControl

In this first campaign a geodetic network was established around the object in order to work always in the same reference frame in the future. Eight points were determined by GPS measurements and transformed into UTM-coordinates, distributed around the village as well nearby the temple. Additional tacheometric measurements were carried out to add more control points to the geodetic net. Furthermore a special network was generated only for the temple itself, to prefer the high precision of the total station measurements for processing of the data in the local network of the temple. This local network consists of seven points in total, which are determined in 3D with an RMSE of $4 \mathrm{~mm}$.

The measurements of the total station were used to determine the UTM-coordinates of the black and white targets used for the registration and geo-referencing of the laser scans. The position of the total station has been determined by free-station method within the geodetic network of the site. Thus, the scans of each scanner position can directly be geo-referenced into the UTM coordinate system using at least four well distributed targets for each scanner station.

\section{DATA ANALYSIS}

The data processing was divided into several tasks. Clearly defined goal of the first object recording should always be an inventory, so a major task was to build a complete and detailed model of the temple for documentation. Although, some maps generated in the last few decades are available (de Maigret \& Robin, 1998), deformations of the facades should be determined 
and visualized for planned restoration and conservation. Moreover, the geo-referenced point cloud was used as a basis for the generation of a virtual model, which describes the current (original) status of the temple.

\subsection{Mesh Modelling}

The modelling of the temple has been performed by 3D triangulation (meshing). The raw data volume of 300 million points was reduced and segmented to 26 million points, where the resolution (grid spacing) was $10 \mathrm{~mm}$. Finally, the virtual model was composed from five separate parts of the temple, the four facades and the ground floor. As a compromise between file size (data volume) and level of detail, a dataset of 12 million triangles was considered as acceptable, especially since parts of the temple can be added to the model using data with even higher resolution. A perspective view of the generated virtual 3D model is illustrated in Figure 5.

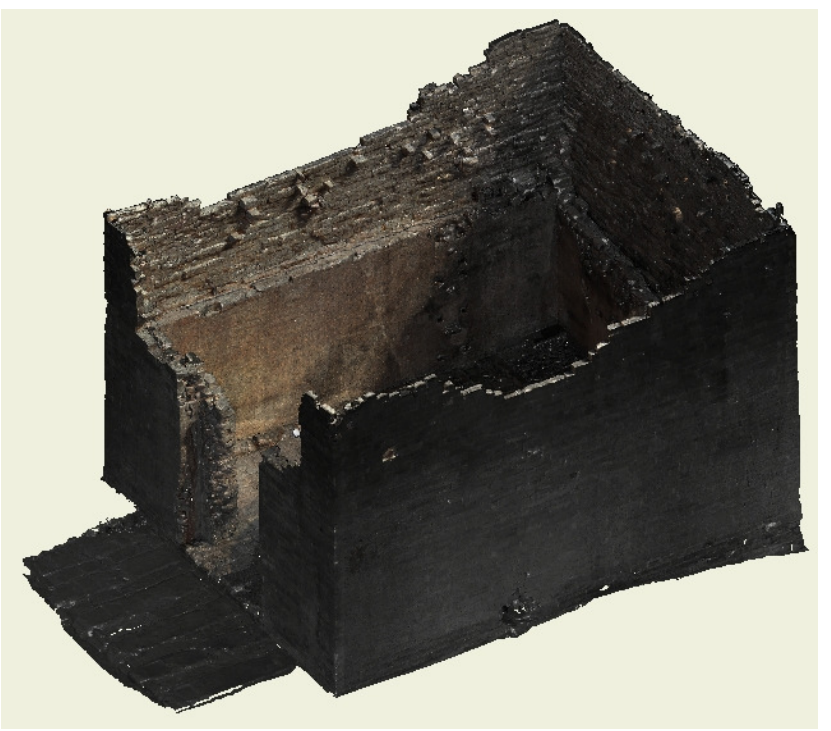

Figure 5: Perspective view of the virtual 3D model of the Almaqah temple, generated as a mesh in the software Geomagic

\subsection{Deformations of the temple facades}

For the planned restoration of the temple a detailed documentation of the current building condition is essential, as well as the detection and quantification of possible hazard sources. Today, the building is freely available to public visitors after the payment of the entrance fee. There are no security or warning advices, although the stones of the walls lie only very loosely together and some dangerous overhangs have been formed. Despite the fact de Maigret \& Robin (1998) concentrated on detailed mapping of the temple, they even have drawn several plans, but they never dealt with its preservation or possible restoration. For restoration reason, deviations from the verticality for each of the temple facades were documented. Therefore, the meshed wall of the constructed virtual model has been compared to each related vertical wall of the ground plan. As a result a colour-coded reference plot was generated, in which the deviations between the meshed northern facade (outside) in comparison to a vertical wall are depicted (Fig. 6).

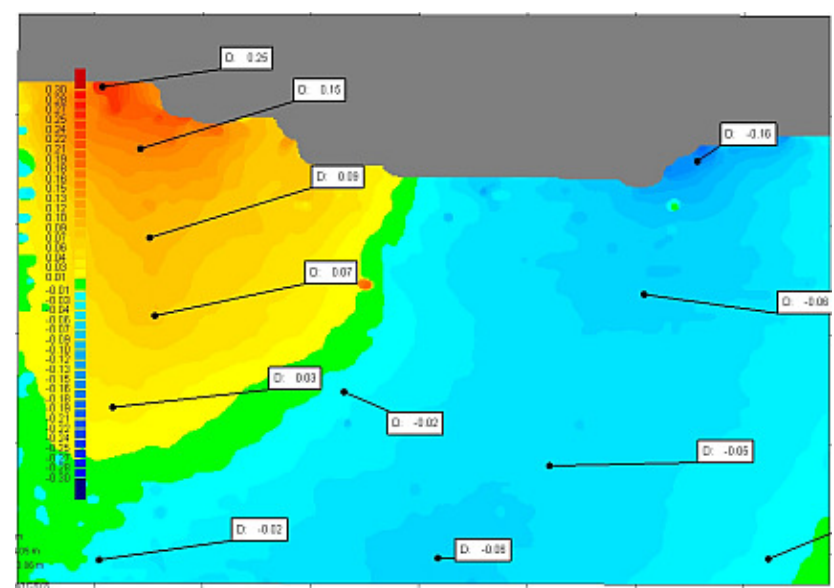

Figure 6: Deviations between the meshed northern façade in comparison to a vertical wall

Additionally, an overhang of about $30 \mathrm{~cm}$ to the outside has been detected at the higher eastern part of the wall, whereas the western part is more inclined to the inside. Furthermore, the variations of the wall thickness were derived from the 3D triangulation of the inner and outer wall, as shown in Fig. 7.

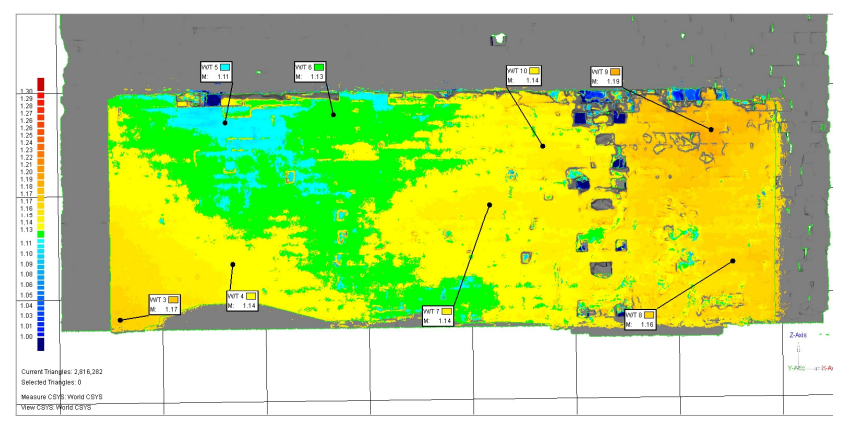

Figure 7: Variations of the wall thickness

Another way to present the deformations is to intersect the point cloud of the temple. Several sections of each temple façade have been produced for more detailed documentation. As an example sections through the eastern façade of the temple are illustrated in Fig. 8. They will be needed for planned static calculations, in order to derive parameters from these calculation for the stabilisation the temple walls. 

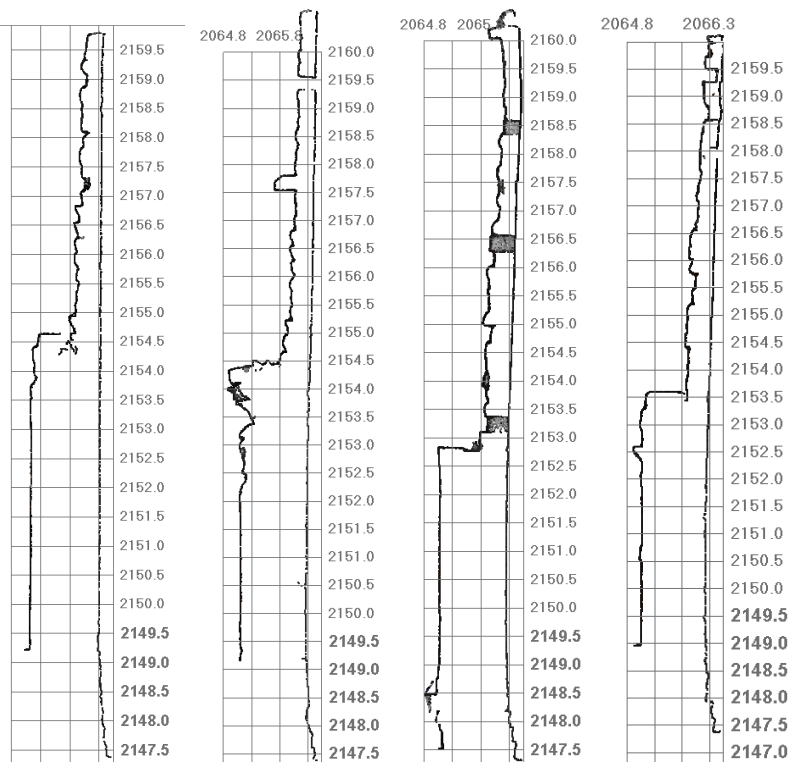

Figure 8: Sections through the eastern façade of the temple

\section{VIRTUAL RECONSTRUCTION}

For the virtual reconstruction not only the 3D scanning work was carried out, but also a historical building research analysis and literature research was done additionally; their results, photos and descriptions were recorded in analogue sketches. They formed the architectural and scientific framework and served as a preliminary stage for the study of the $3 \mathrm{D}$ scan data regarding the reconstruction. Due to the substantial volume of work of a total virtual reconstruction of the temple, at first is has been focused only on the temple entrance. Nevertheless, stepwise reconstruction will lead to the entire model of the former temple. The software packages used for this purpose are LupoScan from Lupos 3D and AutoCAD from Autodesk.

The originally intended method of 3D digitisation and reconstruction directly in Lupos 3D had to be discarded due to a lack of adequate drawing features in the $3 \mathrm{D}$ view of the program. Instead a method was used, in which the different 2D viewing windows were used for $3 \mathrm{D}$ digitisation (vectorisation) of the surfaces in LupoScan and transferred to AutoCAD afterwards. For a sharp and more plastic representation of the individual scans so called spot images were calculated, where the incident angle of the laser spot on the surface was calculated for each pixel and presented in gray values. After the vector data generation, the reconstruction of the former temple shape was accomplished directly in AutoCAD with respect to the results of the architectural and building historical investigations. Therefore it was necessary to take additional measurements in the point cloud. In the entrance area of the temple foundations of columns are located. They suggest the existence of a former propylon, which was already reconstructed as a first step (Fig. 9). The next steps will be the reconstruction of the interior of the temple, since the whole building is restored virtually.

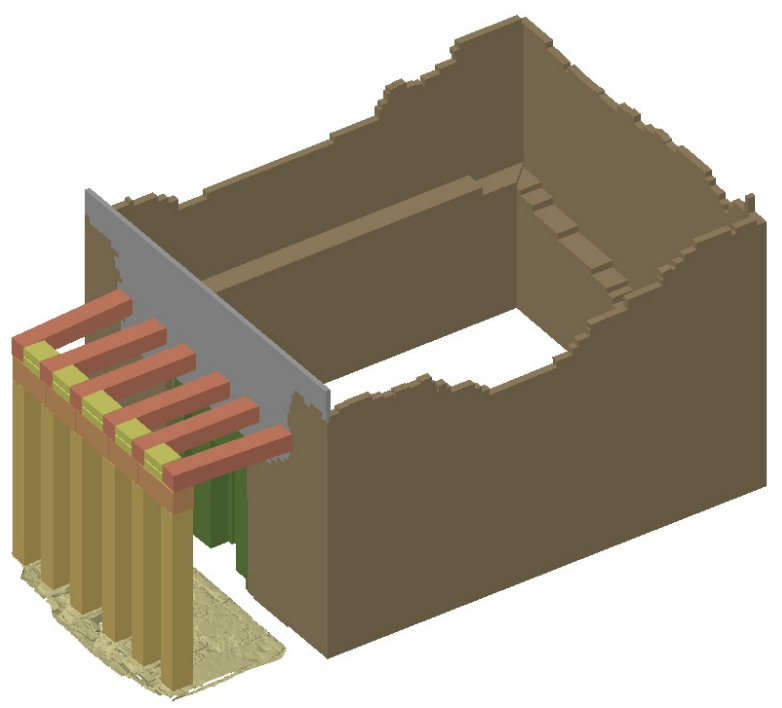

Figure 9: Reconstructed propylon and masonry with the current status of the facades in CAD

\section{CONCLUSION AND OUTLOOK}

For the Almaqah temple of Yeha terrestrial laser scanning has proved to be the ideal acquisition method. Due to sufficient working time on site it was possible to complete the documentation of the current status of the temple in a very high level of detail. The generated point cloud has been used for a variety of tasks; a 3D model was created and a virtual reconstruction of the former temple look was built. With respect to upcoming restoration tasks the deformations of the facades were determined as basis for static calculations.

The presented method offers good possibilities for building researchers to create three dimensional vector data from point clouds. It simplifies the addition of the existing buildings with reconstructive elements in the form of representative 3D models. A direct linking of point clouds and vectors, with the point cloud representing the stock and the vector data representing the reconstruction, is also an interesting combination.

The data generated in this project provides the basis for future measurement tasks, including the documentation of the planned excavation and monitoring of restoration. Furthermore, the model will be the basis data for 3D GIS, which will be used for the documentation and analysis of the archaeological sites.

Finally, the reconstructed model will be prepared for a virtual documentation in the planned museum or for touristic applications, also in the Internet.

\section{REFERENCES}

El-Hakim, S. Beraldin, J.-A., Picard, M., Cournoyer, L., 2008. Surface Reconstruction of large complex Objects from mixed range data - the Erechtheion experience, The International Archives of the Photogrammetry, Remote Sensing and Spatial Information Sciences, Vol. XXXVII, Part B5, pp. 1077-1082.

Kersten, Th., 2007. Virtual Reality Model of the Northern Sluice of the Ancient Dam in Marib/Yemen by Combination of Digital Photogrammetry and Terrestrial Laser Scanning for Archaeological Applications. International Journal of 
Architectural Computing, Special Focus on Cultural Heritage, 02 (05), Multi-Science, pp. 339-354.

Kersten, Th., Mechelke, K., Lindstaedt, M., Sternberg, H., 2009. Methods for Geometric Accuracy Investigations of Terrestrial Laser Scanning Systems. Photogrammetrie Fernerkundung - Geoinformation, Heft 4, pp. 301-316.

Lindstaedt, M., Kersten, Th., Mechelke, K., Götting, M., Heiden, R., 2008. Virtuelles 3D-Modell der antiken Tempelanlage in Sirwah/Jemen zur archäologischen Objektdokumentation durch terrestrisches Laserscanning und Photogrammetrie. Publikationen der Deutschen Gesellschaft für Photogrammetrie, Fernerkundung und Geoinformation e.V., Band 17, Hrsg. E. Seyfert, 28. Wissenschaftlich-Technische Jahrestagung der DGPF, 23.-25. April 2008 in Oldenburg, pp. 59-68.

de Maigret, A. \& Robin, C., 1998. Le grand temple de Yéha (Tigray, Ėthiopie), après la première Campagne de Fouilles de la Mission Française. Comptes-rendus des séances de l'Académie des Inscriptions et Belles-Lettres, Année 1998, Volume 142, Numéro 3, pp. 737-798

Mechelke, K., Kersten, Th., Lindstaedt, M., 2008. Geometrische Genauigkeitsuntersuchungen neuester terrestrischer Laserscannersysteme - Leica ScanStation 2 und $\mathrm{Z}+\mathrm{F}$ IMAGER 5006. Photogrammetrie, Laserscanning, Optische 3D-Messtechnik - Beiträge der Oldenburger 3D-Tage 2008, Th. Luhmann/C. Müller (Hrsg.), Wichmann Verlag, Heidelberg, pp. 317-328.

Remondino, F., Gruen, A., von Schwerin, J., Eisenbeiss, H., Rizzi, A., Girardi,S., Sauerbier, M., Richards-Rissetto, H., 2009. Multi-Sensor 3D Documentation of the Maya site Copan, 22nd CIPA Symposium, October 11-15, 2009, Kyoto, Japan 